\title{
Resilience of Adolescents Survivors of Domestic Violence: A Qualitative Study
}

Intan Maharani Sulistyawati Batubara ${ }^{1 *}$ (D), Novy Helena Catharina Daulima ${ }^{2}$, Ice Yulia Wardani ${ }^{2}$, Heni N. Kusumawati ${ }^{3}$, Setiyawan Setiyawan ${ }^{1}$ (D) Meri Oktariani ${ }^{1}$ D, Eni Rumiyati ${ }^{4}$

${ }^{1}$ Department of Psychiatric and Mental Health Nursing, Universitas Kusuma Husada Surakarta, Surakarta, Indonesia; ${ }^{2}$ Department of Psychiatric and Mental Health Nursing, Universitas Indonesia, Depok, Indonesia; ${ }^{3}$ Department of Psychiatric and Mental Health Nursing, Surakarta State Health Polytechnic, Surakarta, Indonesia; ${ }^{4}$ Department of Midwifery, Universitas Kusuma Husada Surakarta, Surakarta, Indonesia

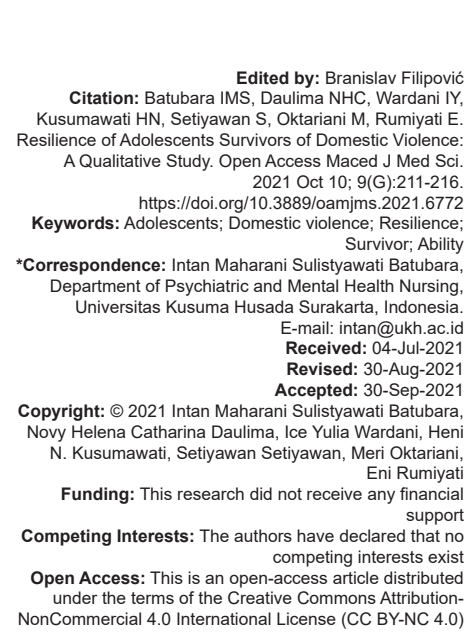

Abstract

BACKGROUND: The ability of adolescents to overcome the impact of domestic violence and reflect on the achievements is a form of resilience.

AIM: The study explored an in-depth description of the discovery process of the resilience ability in adolescent survivors of domestic violence.

METHODS: This qualitative research with a descriptive phenomenology approach interviewed seven adolescent survivors between the ages of 15 and 21 . In-depth interviews were conducted, and demographic data were collected. Interviews were transcribed and coded thematically. Data were analyzed with the method of Colaizzi.

RESULTS: Four themes were derived from the interviews, including painful words from the close family member as a form of intimidation; the emotional response as imprinted feeling caused by the domestic violence; self-struggle starts from their own; and the happiness of the close family member as the purpose of life.

CONCLUSION: Adolescents responses to domestic violence cause mental health problems, however, they also manage to overcome problems, fulfill goals, and review their past and current life events to achieve life's purpose.

\section{Introduction}

Adolescence is a transition period from childhood to adulthood that requires maintaining interpersonal relationships with the environment. Domestic violence is considered an "unseen crime" because it usually occurs inside the house, is blocked by privacy from outside parties, is often witnessed by children who live at home, and has a profound impact on the development of children in all age ranges, including adolescents [1], [2]. Adolescents aged 14-17 years are proven to be the highest group in witnessing the incidence of domestic violence by $32 \%$ [1]. Domestic violence against adolescents not only occurs when adolescents witness domestic violence but also accept violence as indirect victims (parents quarreling) and direct victims (the main target of acts of violence).

The previous study [3] reveals that in families where domestic violence occurs, $90 \%$ of children and adolescents must have witnessed and become victims of violence.
The government's efforts in coordinating with various parties have not reduced the number of domestic violence occurring among adolescents.

Datafound by the office ofwomen'sempowerment, child protection, population control, and Family Planning in 2016 showed that there were 86 new cases in Semarang City out of 592 domestic violence cases against children and adolescents in Central Java Province. Data estimated that up to 1 billion children from 2 to 17 years old were exposed to physical, emotional, sexual violence, and neglect in the past year [4]. One phenomenon that mental health workers in the community had not been involved in providing mental health recovery and empowerment services is the assistance and counseling provided directly by advocates and social workers.

Domestic violence as one of the life-risk adverse situations can affect adolescent life in adulthood and involve physical, psychological, and social function problems. Victims of domestic violence affect self-development, quality of family functions, and the country's economic productivity in a long road. 
However, adolescents can overcome their life's problems by coping strategies as efforts may vary in the normal psychology ability. Those coping strategies are proven to successfully overcome the physical, psychological, and psychological trauma disorders experienced by domestic violence. Adolescents also can pass through unpleasant events, rise, continue living, and build relationships with their environment. The ability to survive the problems experienced is called resilience [5], [6], [7]. This ability makes the adolescents become survivors [8].

A study explains that survivor is a term for people who have experienced abuse and have coping strengths and strategies [9]. Victims who have a history of domestic violence as children and adolescents, the survivors, consciously refuse to pass on violent behavior to their children and create a family climate that ensures the well-being of their children and adolescents [9]. Resilience can be formed in victims of domestic violence in adolescents who are potentially depressed or as an effort of coping strategies that can increase self-esteem. Regarding the existence of selfesteem, adolescents can assess the achievements and efforts made in their life. All those events will guide adolescence to set their purpose in life.

Much research on resilience has been done, but none of the focus on the adolescents' survivors of domestic violence. Previous study [8] found that 145 teens bullying victims aged 12-15 years were able to experience a meaningful life despite being in a difficult life situation and doing a good coping strategy.

\section{Objective}

The objective of the study is to explore qualitatively to provide an in-depth description of the process of discovering the resilience ability in adolescent survivors of domestic violence.

\section{Methods}

This study used a qualitative research method with a descriptive phenomoenology approach. Seven adolescents' survivors of domestic violence were selected by purposive and snowball sampling technique who aged 15-21 years, had been violated by family members within the same household and involved in a certain community organization. Recruitment was based on their contribution as facilitator in a local child center for victims of violence program, in which it met the criteria of survivors. The first author established a good rapport with potential participants by engaging in the program and offered them to participate in the study voluntarily.
The data collection in this research involved two designated pilot areas in Semarang, Indonesia which were Gunungsari and Kuningan. The researcher then performed data analysis with the method of Colaizzi [10] with bracketing, intuiting, analyzing dan describing processes. The process of collecting data through a semi-structured in-depth interview was chosen to capture adolescent's narratives individually [11] and conducted from April 16, 2017, to May 16, 2017. This study was approved by the Committee of Ethics, Faculty of Nursing, Universitas Indonesia.

The study reached four criteria of Lincoln and Guba data validity with credibility, dependability, confirmability, and transferability processes. First, the first author confirmed with participants the suitability of the data based on the results of the transcript. The researcher made conclusions and clarified to the participants by member checking, according to the participants' perceptions. Participants then gave their agreement to the obtained findings. Second, the second and third authors examined the overall activities of the first author during the research process, acting as independent auditors. This study achieved the auditability principle. The audit process in this study was a consultation process with the independent auditors as a form of data validity. Third, confirmability reached as findings of this study referred precisely to the participant's answers recorded and field notes as field observations in which it guaranteed the objectivity of the research results. Finally, the study achieved transferability criteria by displaying a thick description. The words of the participants discussed in the research results were under the emerging themes so that readers can compare the results of other studies. Other studies also support the themes generated in this study according to the transferability criteria. The first author applied it by making a complete and clear report on research results by presenting them in front of independent authors and research examiners at the Faculty of Nursing Universitas Indonesia.

The author obtained informed consent from participants before each interview. Adolescents were able to decide carefully without parental consent regarding their involvement in the study [12], [13]. Participants were informed of the sensitive nature of the interview guide content and given the freedom to withdraw at any stage of the study. Interviews were conducted in places with maximum privacy and strictly maintained the confidentiality of information. An interview guide used included a broad and openended questions which focused on how adolescents viewed the experience of domestic violence. All interviews were carried out in Bahasa Indonesia with a Javanese dialect which lasted from $45 \mathrm{~min}$ to $60 \mathrm{~min}$. The author gathered data until it reached the level of "saturation," which is when new data no longer emerges [14]. This study presented a cash token of Rp 50.000 . 


\section{Results}

The author interviewed seven participantsparticipants ages range from 16 to 21 years of age. There were four females and three males. There was one vocational high school student, five high school graduates, and one dropping out of school. A total of six participants were Javanese, and one participant has Javanese and Arabic ethnicity. Job-status varies from not working, being laid off by layoffs and helping mothers at home, employees of gas stations, dental assistants, and social workers. History of domestic violence experienced on average from childhood to high school age, but some participants experienced domestic violence within 1-2 years, and some even accept this form of violence. Perpetrators of violence mostly fathers; a few other participants described brother and mother as perpetrators of violence. The conditions of domestic violence that more than seven participants received were physical violence, accompanied by six participants' verbal violence, and two participants were intimidated. which were:

Four themes were derived from the interviews,

\section{Painful words from the close family} member as a form of intimidation, as stated in the following participant

“... like asu (dog), when my mother was angry with me because I had played from morning to night... My mother was looking for me and couldn't find me... and when I went back home, my motther were really angry and said hurtful things like I act like a dog. I was thrown out; I was not allowed to enter the house. She said that I should not have to come home again and told me to go with my friend instead. " (P1)

“... Then, when I was going to take a shower, my brother was behind me and threatened me by saying, If you pass by, I'll throw water on you ..." (P5)

McKenna, O'Connor and Verco [15] described painful words experienced by the victims as threats. The beginning of violent acts on domestic violence can create its cycle.

\section{The emotional response as imprinted feeling caused by the domestic violence, as stated in the following participant}

“...I feel disappointed though, because... why should I be beaten, they can talk nicely instead" (P2)

“...but I had been trying... people don't know... they don't know how sad I am, I just let them know that I'm happy... (P3)

“... until now, I still feel depressed when I was at home. I still dont feel ease in my house, no sense of comfortness at all." (P5)
This study found that the act of domestic violence affects emotional problems, which harm the adolescent themselves and affect the decline of behavior [16] and the loss of social relations with the environment. Adolescents then consider that domestic violence is not a tolerable act.

\section{Self-struggle starts from their own, as stated in the following participant}

“... that domestic violence may indeed hurt, maybe it still scares us, but it too can pass... if we do not dare to move or fight againts it... every day or even every time will always be like this (P4)."

"The wisdom is... I can be an example to others... if we become victims of domestic violence, we can show a positive thing... who turned hate into affection." (P7)

Although participants in this study experienced emotional imprinted feelings, they had the ability to overcome life problems through coping strategies and can be referred to as survivors [9]. This study found that adolescents made several efforts to overcome the effects of domestic violence with building relationship with social environment [17]

The happiness of the close family member as the purpose of life, as stated in the following participant

“... For me, my first first goal is still my family, my family happiness, especially my mother... since I was a child untill now it did not change, she even had to struggle and cannot live well... I really want her to be happy."(P7)

"...happiness can motivate us more, encourage us more to be better... and be the best for the family." (P4)

Close family members mean the importance of social support existence [18] which can be trusted and helpful when needed.

\section{Discussion}

First theme found was painful words from the close family member as a form of intimidation. Verbal abuse is regarded as psychic violenceand accompanying other acts of violence. McKenna et al., [15] define verbal violence as one form and psychological torture such as shouting, arguing, challenging, belittling, mocking, and abusing. Teicher et al., [19] reinforced the statement that the impact of verbal violence experienced by youth victims of domestic violence caused an injury that imprints adolescents' psychic health. This is because 
parents' verbal abuse of adolescents and young adults can result in depression, withdrawal, and symptoms of anger and hostility.

The study finds that painful words such as abusive and inappropriate humiliation, threats of violence, and expulsion are a form of intimidation of close family members as perpetrators of domestic violence to adolescents as victims. Smith [20] describe threats and verbal abuse as the beginning of domestic violence to create a cycle. The Domestic Violence Cycle illustrates that acts of violence are the perpetrators' choices to control their victims. They attempt to dominate, humiliate, isolate, threat, intimidate, deny and blame to manipulate and use their power against victims. Thus, the perpetrators of violence will carry out various acts of violence to control, manipulate and maintain dominance to the victim. Therefore, the victim cannot resist the perpetrators of violence both physically and psychologically.

Second theme found was the emotional responses as imprinted feelings caused by the domestic violence. The study found that the seven participants' emotional responses were discomfort, irritation, disappointment, sadness, hurt, resentment, distress, frustration, and imprinting, causing the desire to leave home and trauma [16]. Adolescent victims of domestic violence will feel mental health problems such as fear and anxiety [21]. Adolescents will always feel alert, look, and wait for what events will happen. Adolescents cannot predict the reasons that trigger further domestic violence so that they will never feel safe. Adolescents will always worry about themselves and the other family members, who happen to be the victims of domestic violence, such as mother, brother, or sister. Adolescents will also feel worthless and helpless.

Adolescents may experience "double whammy" psychological effects of internalizing behavior and externalizing behaviors from the social environment [22], [23]. In this study, one of the participants revealed an emotional response that felt ambitious, never accept any loss, and using violence as the only way to handle the problem. Researchers categorize this response as an externalizing behavior risk that, if not addressed immediately, not only threatens adolescents as victims but also can turn adolescents into perpetrators of violence. This is also reinforced by [9] which explains that juvenile offenders who come from families consider violence as acceptable behavior. Domestic violence is indirectly justified for aggressive behavior.

Third theme found was self-struggle starts from their own. Self struggle is one of the efforts processes to overcome the effects and recover victims of domestic violence [24]. Firstly, adolescents' attempt to distance themselves as an escape of domestic violence and divert on the positive side to create a positive look [25]. Secondly, they prevent and stop the act of domestic violence by self-struggle. One of the participants in the study mentioned that one effort made to prevent domestic violence was the courage to fight. This study found that participants expressed the ability to resist, prevent violence, dare to move, wanting to rise, fight, be strong and endure. United Nations Children's Fund [24] mentions one attempt to prevent and stop the violence is to help children and youth have coping strategies by raising awareness not to use violence to solve problems and seek help from others when subjected to violence.

Thirdly, adolescents build a relationship with a social environment [17]. One of the participants mentioned that they wanted to be an example for others. One other participant also said that they wanted to show a positive thing, even though being a victim of domestic violence, they can be a person who can turn hate into affection.

As whole participants here engaged in the certain organization of a local child center for victims of violence program in two designated areas, they have the motivation to give a positive outlook, be an example for others, and rise [26].

Fourth, domestic violence victims do hobbies. Participants mentioned playing music or swimming to overcome the effects of domestic violence. Flannery et al., [27] explain that doing hobbies can cope with stress, psychological trauma and prevent the desire to engage in violent behavior.

Fifth, the self-acceptance as possitive self-defense [28]. Ellis [29] also explains that selfacceptance can optimize the social function of human beings as social beings. Participants revealed that with self-acceptance, they were able to cope and reconciled with the events of domestic violence and the impact they have experienced.

This study explains that although adolescents receive physical, psychological, and socially functional trauma, they can still perform positive coping strategies. Then, adolescents reflect to improve their ability to do coping strategies and view success and failure as wisdom. Adolescents further reappraisal themselves by reassessing failure and coping strategies that have been experienced for better learning in the future [30].

The whole five process to overcome effects and recover from domestic violence is a self-awareness. This awareness to prevent, reduce and stop violence is an effective coping strategy to stop the cycle of domestic violence. The desire of adolescents to fight against violence is an adaptive coping strategy. Adolescents have an awareness that domestic violence should be stopped, and adolescents can cope with the effects of domestic violence as a problem that must be overcome positively. All struggles to overcome the impact of domestic violence are evidence that adolescents can pass through unpleasant events, rise, and continue living as resilient from their battle.

Resilience is formed in individuals who have risky life problems (highrisk adverse events) rather than individuals experiencing a low-risk (low-risk) issue events) [31]. Resilience appears in late teens (early 20s) 
until early adulthood (20s/early 30 s) on more stable emotional states. According to [5], [6], [32] resilience is formed as a self-defense effort to deal with depression and increase self-esteem in children and young people victims of domestic violence. Other findings show that despite the history of domestic violence experienced as a child and adolescent and at risk of having an onset of events depression 10-15 years after entering adulthood, domestic violence victims can go through adverse life events with constructive self-esteem [33], [34]. In short, the self-struggle starts from adolescence as their way to self-defense effort of resilient ability.

Four theme found was self-struggle starts from their own. This study found the happiness of the close family member is the purpose of life. This study found that the participant's life goals were demonstrated by creating happiness for the close family member such as mother, father, brother, and sister. The expression of the seven participants, such as the desire to raise the parent's economic welfare, pleasing parents and family, the desire not to burden the parents, parental repayment, and guarding the family, led the expression of adolescent to the happiness of the nearest person to be achieved.

This study concludes that a close family member's happiness as an achieved life goal is considered necessary, valuable, motivating, worth everything, or even as a life purpose. Previous study explained that adolescents will build a perspective that suits themselves (meaning life) and begins to achieve goals that fit with the perspective (purpose of life) [35]. This statement is in accordance with Frankl (1970) [18], which explains that the effort to set the goal of life gives unique value to a person as the motivation, intent, and the main desire that everyone must achieve. Thus, the close family member's role as the goal of adolescent survival of young adolescent of domestic violence is the achievement that adolescence wants to achieve as the purpose of life.

On an observational note, the author noticed that all participants seemed reluctant at first to share their experience as victim of domestic violence. Some of them stated that they felt embarrassed to speak up about what the perpetrators did to them since the perpetrator of violence is a significant other (s). However, the author overcomes the limitation by establishing a good rapport by hanging out with them outside the program activity. Further, due to the sensitivity of the research topic, this study had limitation of a small sample size. Thus, our sample may not represent all participants as the generalizability of its results is limited.

\section{Conclusion}

This study conlude that adolescence is unable to fight both physically and psychologically against the perpetrators of violence, in which their responses to domestic violence cause mental health problems. Adolescence will always be vigilant, never feel safe and feel worthless and helpless, however, they will also seek to overcome the problem of life with the self-awareness to prevent, reduce, and stop the violence. In the end, they can fulfill their goals and reviewing all the past and presents events of their life. Future research should use a larger sample and identify adolescents' characteristics and contributing factors to the exploration of purpose of life.

\section{Acknowledgments}

The first author received financial support from Universitas Kusuma Husada Surakarta, Indonesia for research, authorship, and publication. The authors are grateful to all subjects participating in this study.

\section{References}

1. Finkelhor D, Turner HA, Shattuck A, Hamby SL. Prevalence of childhood exposure to violence, crime, and abuse: Results from the national survey of children's exposure to violence. JAMA Pediatr. 2015;169(8):746-54. https://doi.org/10.1001/ jamapediatrics.2015.0676

PMid:26121291

2. Hall CM. Adolescents Exposed to Domestic Violence: The Development of a Treatment Manual. San Francisco Bay: Alliant International University; 2006.

3. Fusco RA, Fantuzzo JW. Domestic violence crimes and children: A population-based investigation of direct sensory exposure and the nature of involvement. Child Youth Serv Rev. 2009;31:249-56. https://doi.org/10.1016/j.childyouth.2008.07.017

4. Hillis S, Mercy J, Amobi A, Kress H. Global prevalence of past-year violence against children: A systematic review and minimum estimates. Pediatrics. 2016;137(3):e20154079. https://doi.org/10.1542/peds.2015-4079

PMid:26810785

5. Eisman AB, Stoddard SA, Heinze J, Caldwell $\mathrm{CH}$, Zimmerman MA. Depressive symptoms, social support, and violence exposure among urban youth: A longitudinal study of resilience. Dev Psychol. 2015;51(9):1307-16. https://doi. org/10.1037/a0039501

PMid:26147772

6. Loh JM, Schutte NS, Thorsteinsson EB. Be happy: The role of resilience between characteristic affect and symptoms of depression. J Happiness Stud. 2014;15:1125-38. https://doi. org/10.1007/s10902-013-9467-2

7. Smith BW, Dalen J, Wiggins K, Tooley E, Christopher P, Bernard J. The brief resilience scale: Assessing the ability to bounce back. Int J Behav Med. 2008;15(3):194-200.

8. O'Donnell MB. The Impact of Bullying and Act Variables on Meaning in Life for Asolescents; 2015.

9. Stuart GW. Principles and Practice of Psychiatric Nursing $10^{\text {th }}$ ed. St. Louis: Elsevier; 2012. 
10. Polit DF, Beck CT. Nursing research: Generating and Assessing Evidence for Nursing Practice. $10^{\text {th }}$ ed. Philadelphia, PA: Wolters Kluwer; 2017.

11. Levey EJ, Oppenheim CE, Lange BC, Plasky NS, Harris BL, Lekpeh GG, et al. A qualitative analysis of factors impacting resilience among youth in post-conflict Liberia. Child Adolesc Psychiatry Ment Health. 2016;10:26. https://doi.org/10.1186/ s13034-016-0114-7 PMid:27525038

12. Santelli JS, Smith Rogers A, Rosenfeld WD, DuRant RH, Dubler N, Morreale M, et al. Guidelines for adolescent health research. A position paper of the society for adolescent medicine. J Adolesc Health. 2003;33(5):396-409. PMid:14596961

13. Spriggs $M$. Ethical difficulties with consent in research involving children: Findings from key informant interviews. AJOB Prim Res 2010;1:34-43. https://doi.org/10.1080/21507711003754526

14. Corbin J, Strauss A. Basics of qualitative research. In: Techniques and Procedures for Developing Grounded Theory. $3^{\text {rd }}$ ed. United States: SAGE; 2008. https://doi.org/10.1525/ jer.2011.6.4.68

15. McKenna M, O'Connor R, Verco J. Exposing the Dark Side of Parenting: A Report of Parents' Experiences of Child And Adolescent Family Violence; 2010.

16. Sternberg KJ, Lamb ME, Guterman E, Abbott CB, Dawud-Noursi S. Adolescents' perceptions of attachments to their mothers and fathers in families with histories of domestic violence: A longitudinal perspective. Child Abus Negl. 2005;29(8):853-69. https://doi.org/10.1016/j.chiabu.2004.07.009 PMid:16126269

17. Saleh Baqutayan SM. Stress and coping mechanisms: A historical overview. Mediterr J Soc Sci. 2015;6(2):479-88. https://doi.org/10.5901/MJSS.2015.V6N2S1P479

18. Bastaman HD. LOGOTERAPI: Psikologi untuk Menemukan Makna Hidup dan Meraih Hidup Bermakna. Jakarta: Raja Grafindo Persada; 2007.

19. Teicher $\mathrm{MH}$, Tomoda A, Andersen SL. Neurobiological consequences of early stress and childhood maltreatment: Are results from human and animal studies comparable? Ann NY Acad Sci. 2006;1071:313-23. https://doi.org/10.1196/ annals.1364.024 PMid:16891580

20. Melinda Smith MA. Domestic Violence and Abuse: Are You or Someone You Care About in an Abusive Relationship? 2016. p. $1-10$.

21. Springer KW, Sheridan J, Kuo D, Carnes M. The long-term health outcomes of childhood abuse. An overview and a call to action. J Gen Intern Med. 2003;18(10):864-70. https://doi. org/10.1046/j.1525-1497.2003.20918.x
22. Levesque RJ, editor. Encyclopedia of Adolescence. $2^{\text {nd }}$ ed. Berlin, Heidelberg: Springer International Publishing; 2018.

23. Moylan CA, HerrenkohI TI, Sousa C, Tajima EA, Herrenkohl RC, Russo MJ. The effects of child abuse and exposure to domestic violence on adolescent internalizing and externalizing behavior problems. J Fam Violence. 2010;25(1):53-63. https://doi. org/10.1007/s10896-009-9269-9

PMid:20495613

24. UNICEF. Ending Violence Against Children: Six Strategies for Action; 2014.

25. Mitchell D. Stress, Coping, and Appraisal in an HIV-Seropositive Rural Sample: A Test of the Goodness-of-Fit Hypothesis; 2004. p. 1-120.

26. Holt JR. The Experiences of Resilience and Hope of Adolescent Girls who have been Victims of Sex Trafficking in the United States; 2015.

27. Flannery DJ, Singer M, Williams L, Castro P. Adolescent violence exposure and victimization at home: Coping and psychological trauma symptoms. Int Rev Victimol. 1998;6:29-48. https://doi. org/10.1177/026975809800600103

28. Rigby K, Bortolozzo G. How schoolchildren's acceptance of self and others relate to their attitudes to victims of bullying. Soc Psychol Educ. 2013;16:181-97. https://doi.org/10.1007/ S11218-013-9213-Y

29. Ellis LK. Individual differences and adolescent psychosocial development. Diss Abstr Int B Sci Eng. 2003;63:3956.

30. Zimmer-Gembeck MJ, Skinner EA. Adolescents coping with stress: Development and diversity. School Nurse News. 2010;27:23-8.

31. Tiet $Q Q$, Bird HR, Davies M, Hoven C, Cohen P, Jensen PS, et al. Adverse life events and resilience. J Am Acad Child Adolesc Psychiatry. 1998;37(11):1191-200. https://doi. org/10.1097/00004583-199811000-00020 PMid:9808931

32. Smith KP, Christakis NA. Social networks and health. Annu Rev Sociol. 2008;34:405-29.

33. Çelik DA, Çetin F, Tutkun E. The role of proximal and distal resilience factors and locus of control in understanding hope, self-esteem and academic achievement among Turkish preadolescents. Curr Psychol. 2015;34(2):321-45. https://doi. org/10.1007/s12144-014-9260-3

34. Yip T. The effects of ethnic/racial discrimination and sleep quality on depressive symptoms and self-esteem trajectories among diverse adolescents. J Youth Adolesc. 2015;44(2):41930. https://doi.org/10.1007/s10964-014-0123-x PMid:24682960

35. Damon W, Menon J, Bronk KC. The development of purpose during adolescence. Appl Dev Sci. 2003;7(3):119-28. https://doi. org/10.1207/S1532480XADS0703_2 